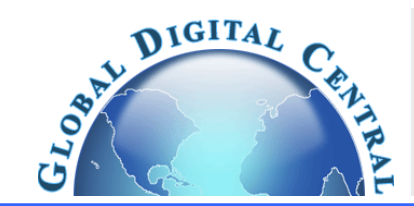

Frontiers in Heat and Mass Transfer

\title{
THERMAL PERFORMANCE IMPROVEMENT IN A SQUARE CHANNEL HEAT EXCHANGER WITH VARIOUS PARAMETERS OF V-WAVY PLATES
}

\author{
Amnart Boonloi ${ }^{\mathrm{a}}$ and Withada Jedsadaratanachai ${ }^{\mathrm{b}, *}$ \\ ${ }^{a}$ Department of Mechanical Engineering Technology, College of Industrial Technology, King Mongkut's University of Technology North Bangkok, \\ Bangkok 10800, Thailand \\ ${ }^{b}$ Department of Mechanical Engineering, Faculty of Engineering, King Mongkut's Institute of Technology Ladkrabang, Bangkok 10520, Thailand
}

\begin{abstract}
Numerical examinations on flow and heat transfer behaviors in a square channel heat exchanger equipped with various configurations of V-wavy plate are performed. The pitch-to-channel height ratios, wavy height-to-channel height ratios and flow directions of the test section are investigated for the Reynolds number in the range of $100-1000$ (laminar flow regime). The finite volume method is selected for the present investigation. The results are reported in terms of flow and heat transfer mechanisms in the channel. The thermal performance assessments of the square channel fitted with the V-wavy plate are also concluded. As the numerical results, the V-wavy plate can produce the swirling flow through the heating channel. The swirling flow disturbs the thermal boundary layer on the heat transfer surface that leads to enhance heat transfer rate and thermal efficiency.
\end{abstract}

Keywords: V-wavy plate; heat transfer; thermal efficiency; square channel; swirling flow.

\section{INTRODUCTION}

The understanding on flow and heat transfer mechanisms in the heat exchanger section is an important way to develop the heat transfer rate and thermal performance of the heat exchanger. Therefore, the investigations on flow and heat transfer in the heating section had been extremely reported. Many researchers try to study on flow and heat transfer behaviors in the test section with various conditions by both numerical and experimental methods. The selection of the vortex generator or turbulator to increase heat transfer rate and efficiency in the heat exchanger is another section, which is interesting for many investigators. The insertion of the rib, baffle, winglet, etc., in the heat exchanger can improve the heat transfer rate due to the disturbance of the thermal boundary layer by the vortex flow, which is generated by the vortex generator. The choose of the vortex generator for the heat exchanger must consider various factors such as the placement of the vortex generator in the heating section, maintenance method, cost, the manufacturing of the vortex generator, etc. The appropriate vortex generator for each type of heat exchanger must be considered.

In the present investigation, the manufacturing of the vortex generator is emphasized. The wavy surface is selected to increase the heat transfer rate and thermal efficiency in the heat exchanger square channel. The insertion method in the middle of the square channel is selected for the heating system. In general, the wavy surface always uses to enhance heat transfer rate in the fin-and-tube heat exchanger, which is called wavy fin. The examples of the studies can conclude as follows;

Priyam and Chand (2018) reported the effects of wavelength and amplitude of wavy finned absorber solar air heater on thermal performance. They found that the thermal performance decreases when increasing the wavelength, but increases when augmenting the amplitude. They concluded that the modified solar air heater gives higher thermal performance than the general type. Li et al. (2018) investigated the heat transfer rate and friction loss of the fin-and-tube heat exchanger equipped with radiantly arranged winglets around each tube. The wavy fin and plain fin were compared on the Nusselt number and friction factor for both numerical and experimental investigations. They concluded that the heat transfer rate and pressure loss for the proposed fin with five-row tubes are almost the nearly as the six-row tubes wavy heat exchanger surfaces. Priyam and Chand (2016) concluded the influences of mass flow rate and fin spacing on heat transfer rate and thermohydraulic performance of the wavy finned absorber solar air heater. Zhan et al. (2016) experimentally investigated the distribution of the particles in the wavy fin-and-tube heat exchanger. Duan et al. (2016) numerically studied on laminar flow and heat transfer in the fin side of the wavy finned flat tube heat exchanger. The effects of fin spacing, wave spacing, and wave amplitude on flow and heat transfer mechanisms were investigated. The numerical results were compared with the experimental results. They reported that the wavy fin can improve the heat transfer rate higher than the plain fin. They also suggested the optimum conditions of the best thermal performance for the wavy finned flat tube heat exchanger for their investigated range. $\mathrm{Xu}$ et al. (2015) experimentally examined the thermal performance improvement of the wavy finned flat tube heat exchanger. They claimed that the thermal performance factor for all types of the wavy fin is higher than 1. Zhang et al. (2016) performed the numerical and experimental investigations of the wavy fin-and-tube intercooler on flow and heat transfer configurations. Kim et al. (2016) numerically studied the heat transfer augmentation by cross cut flow control in the wavy fin heat exchanger. They summarized that the thermal performance of the optimized cross-cut flow wavy fin is around $23.81 \%$ higher than the general wavy fin. Xiao et al. (2017) experimentally examined the heat transfer increment in the wavy finned flat tube by water spray cooling. Khoshvaght-Aliabadi et al. (2016) selected the passive method (perforation winglet) to improve the thermal efficiency of the wavy plate-fin heat exchanger. They studied the effects of the

*Corresponding author. Email: kjwithad@kmitl.ac.th 
waviness aspect ratios $(0.33,0.42$, and 51$)$ with the diameter of the perforation of $5 \mathrm{~mm}$ and the width/height of the winglets of $5 \mathrm{~mm}$. The Reynolds number in the range of 3900 to 11,400 was considered. They concluded that the maximum thermal enhancement factor is found to be around 1.26 at the lowest Reynolds number and at the highest waviness aspect ratio. Lotfi et al. (2016) investigated the thermo-hydraulic performance improvement in the wavy fin-and-elliptical tube heat exchanger combined with the new type vortex generator. The winglet was selected for their investigation to enhance the heat transfer rate and thermal performance of the wavy fin-and-tube heat exchanger. Du et al. (2014) and Du et al. (2013) selected the punched longitudinal vortex generator to increase the heat transfer rate of the wavy finned flat tube heat exchanger. They concluded that the average performance evaluation criteria or PEC can be up to 1.31 with six delta winglet pairs punched on the wavy fin surface. Song et al. (2015) presented the numerical investigation on heat transfer rate, pressure loss and thermal efficiency in the wavy fin channels of a compact heat exchanger. The effects of the channel space, wavelength ratio and amplitude ratio on heat transfer rate and friction loss were studied. They concluded that the new type of the wavy-fin channel can help to decrease the pressure loss around $54 \%$ and to enhance the heat transfer rate around $26 \%$. They also reported the optimal conditions for the wavy-fin heat exchangers in the range investigation.

For the present work, the combination of the wavy surface and Vshape configuration is performed to change the flow and heat transfer structures in the heating section. The present vortex generator is called "V-wavy plate". The V-shaped configuration is selected due to this configuration gives high effectiveness when compared with the other shapes. The parameters of the V-wavy plate such as blockage ratio, pitch spacing ratio and flow direction are investigated numerically. The numerical results can export in the forms of flow and heat transfer visualizations in the heating section. The present results are also compared with the smooth square channel with no generators. The knowledge of the flow and heat transfer structures in the heat exchanger when inserted with the vortex generator may help to improve the new design of the heat exchanger.

\section{Channel walls}
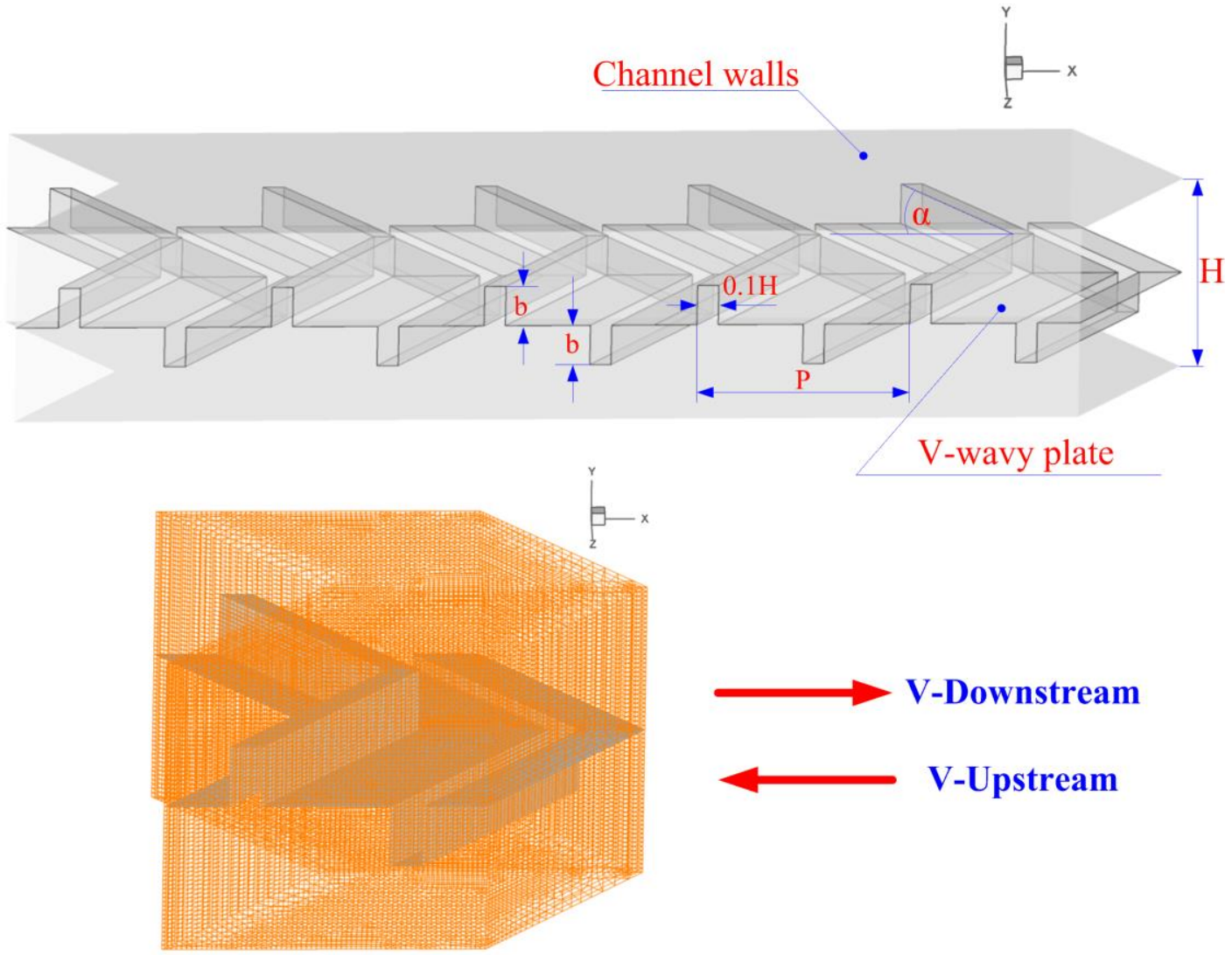

\section{Computational model}

Fig. 1 Computational model of the square channel heat exchanger equipped with $\mathrm{V}$-wavy plate.

\section{PHYSICAL MODEL}

The physical model for the present investigation is a square channel inserted with $\mathrm{V}$-wavy plate at the middle of the channel. The wavy height is represented with "b", while the square channel height is represented with " $\mathrm{H}$ ". The square channel height is around $0.05 \mathrm{~m}$. The ratio between the wavy height and square channel height, $\mathrm{b} / \mathrm{H}$, is called blockage ratio or BR. The blockage ratio is varied, $\mathrm{BR}=0.10-0.30$. $\mathrm{P}$ is pitch spacing ratio between the wavy amplitude. The pitch-to-channel height ratio or $\mathrm{P} / \mathrm{H}$ is called pitch ratio or $\mathrm{PR}$. The pitch ratio is varied from $0.5-1.5$. The laminar flow regime with the Reynolds number in the range $100-1000$ is considered. The effects of the flow directions; V-tip pointing upstream (V-Upstream) and V-tip pointing downstream (V-Downstream), are investigated. The flow attack angle of the $\mathrm{V}$-wavy plate is fixed at $45^{\circ}$ for all investigated cases. The wavy thickness of the $\mathrm{V}$-wavy plate is around $0.1 \mathrm{H}$. The physical domain for the square channel equipped with the V-wavy plate is depicted as Fig. 1.

\section{ASSUMPTION, INITIAL CONDITION AND BOUNDARY CONDITION}

In the present study, the air is selected as the tested fluid. The properties of the air are assumed to be constant at the average bulk mean temperature at $300 \mathrm{~K}$ with the Prandtl number of 0.707 . The flow and heat transfer are steady in three dimensions. The test fluid is set with incompressible condition. Laminar flow regime is considered with the Reynolds number in the range 100 to 1000 . The forced convective heat transfer is regarded, while the radiation, natural convection, viscous dissipation and body forced are ignored. For the computational model, 
the periodic condition is set for the inlet and outlet of the computational domain. The constant temperature around $310 \mathrm{~K}$ is set for all sides of the channel walls. The V-wavy plate is set as an insulator. No slip wall condition is set for the computational surfaces.

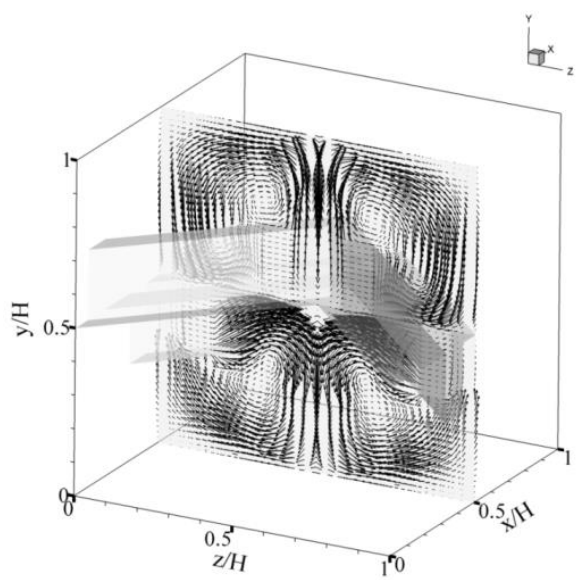

(a)

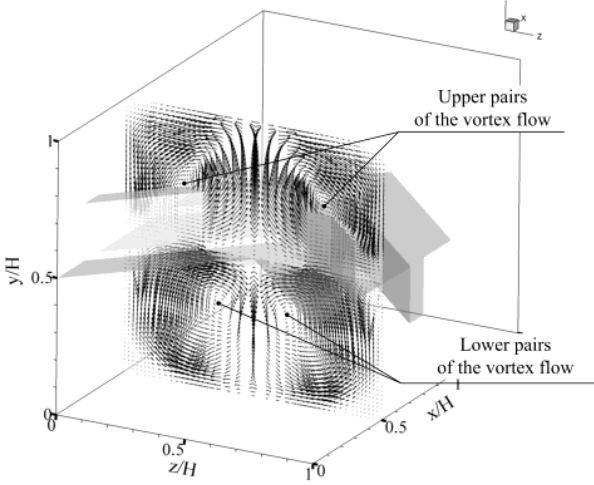

(b)

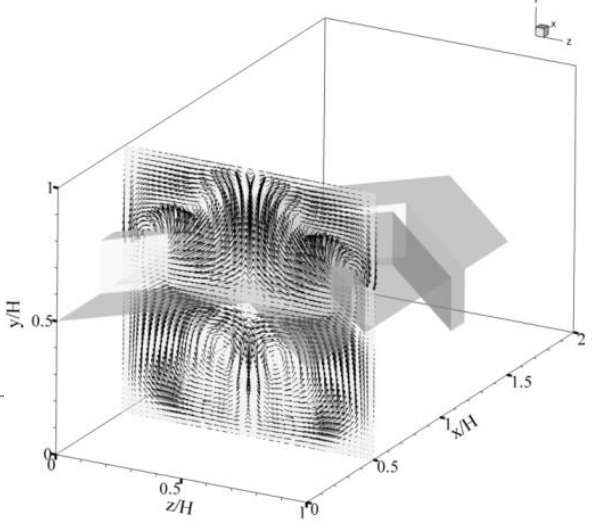

(c)

Fig. 2 Tangential velocity vector in transverse plane in the square channel equipped with V-wavy plate for (a) $P R=0.5$, (b) $P R=1$ and (c) $P R=$ 1.5 at $\mathrm{BR}=0.2, \mathrm{Re}=600$ with V-Downstream arrangement.

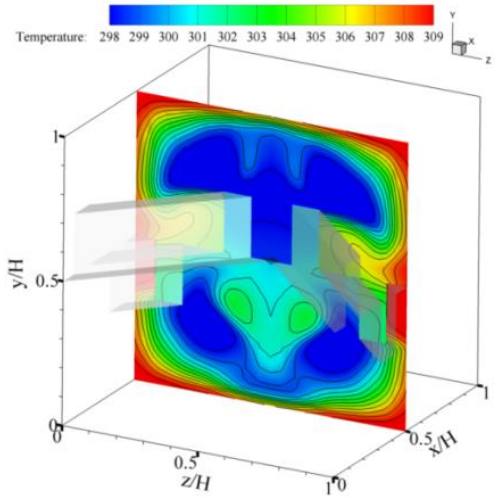

(a)

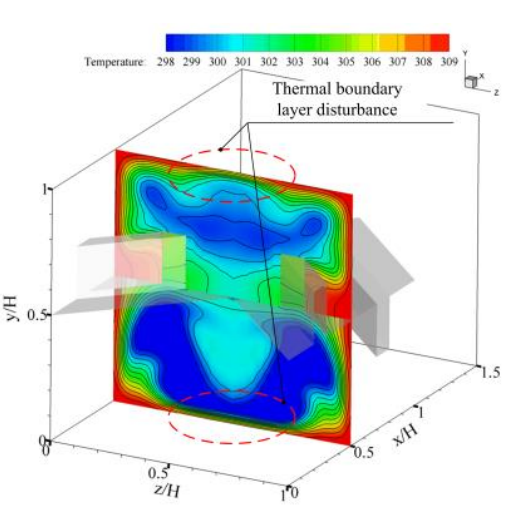

(b)

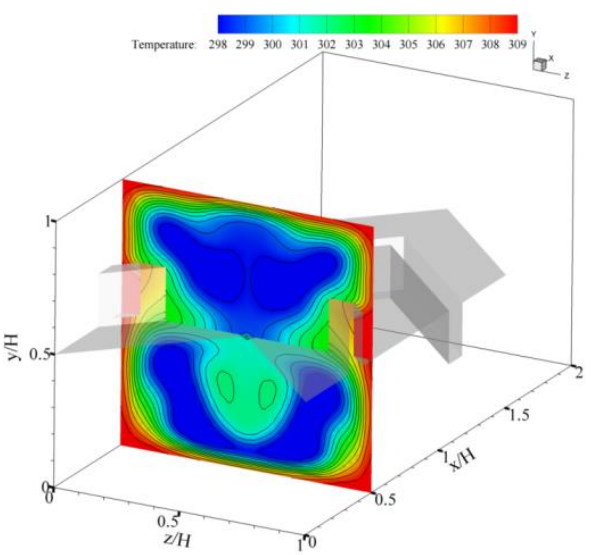

(c)

Fig. 3 Temperature distribution in transverse plane in the square channel equipped with $V$-wavy plate for (a) $P R=0.5$, (b) $P R=1$ and (c) $P R=$ 1.5 at $\mathrm{BR}=0.2, \mathrm{Re}=600$ with $\mathrm{V}$-Downstream arrangement.

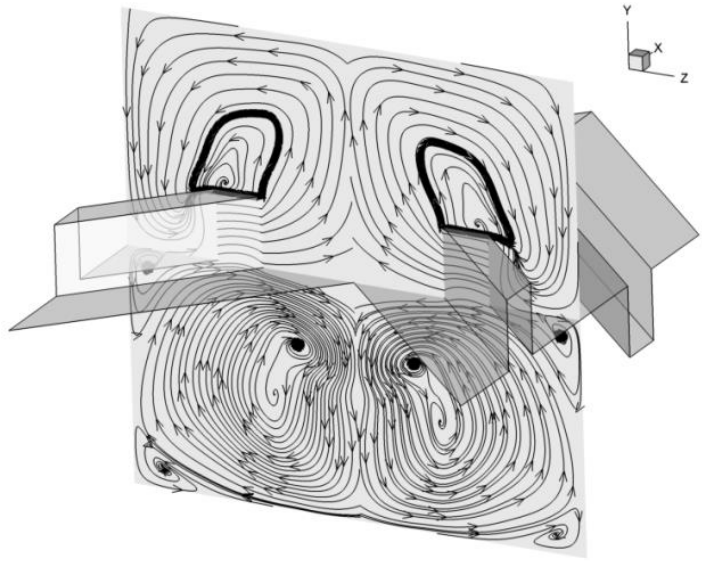

(a)

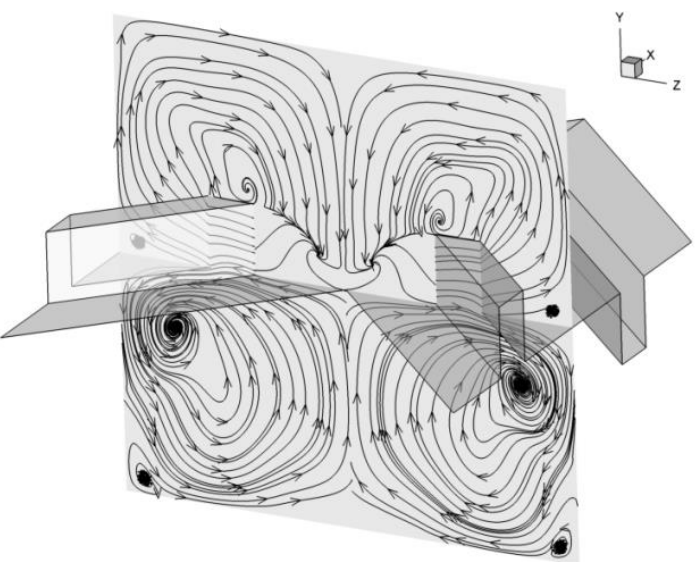

(b)

Fig. 4 Streamlines in transverse plane in the square channel equipped with V-wavy plate for (a) V-Downstream and (b) V-Upstream, at BR = $0.15, \mathrm{Re}=600$ and $\mathrm{PR}=0.5$. 


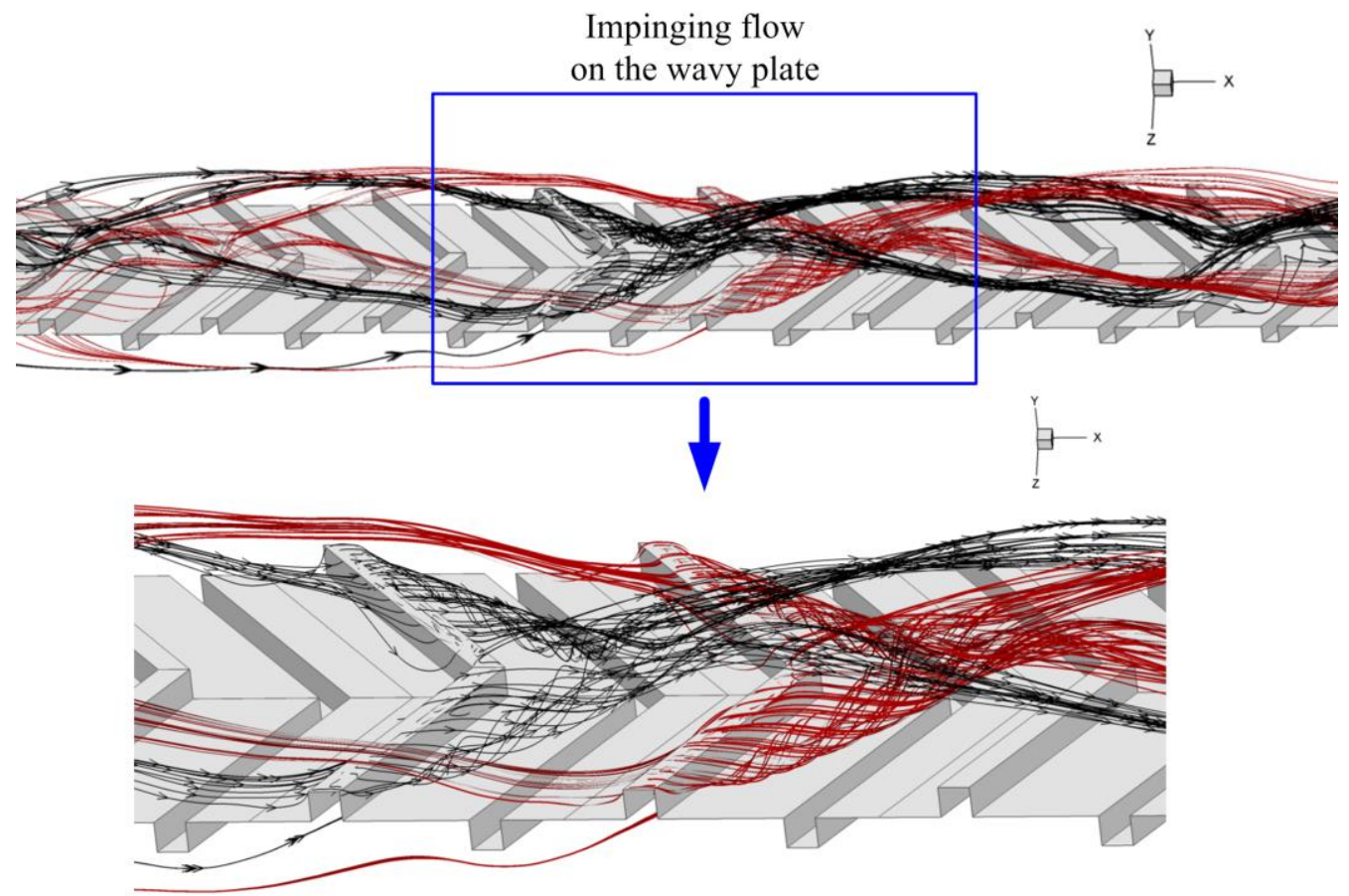

(a)

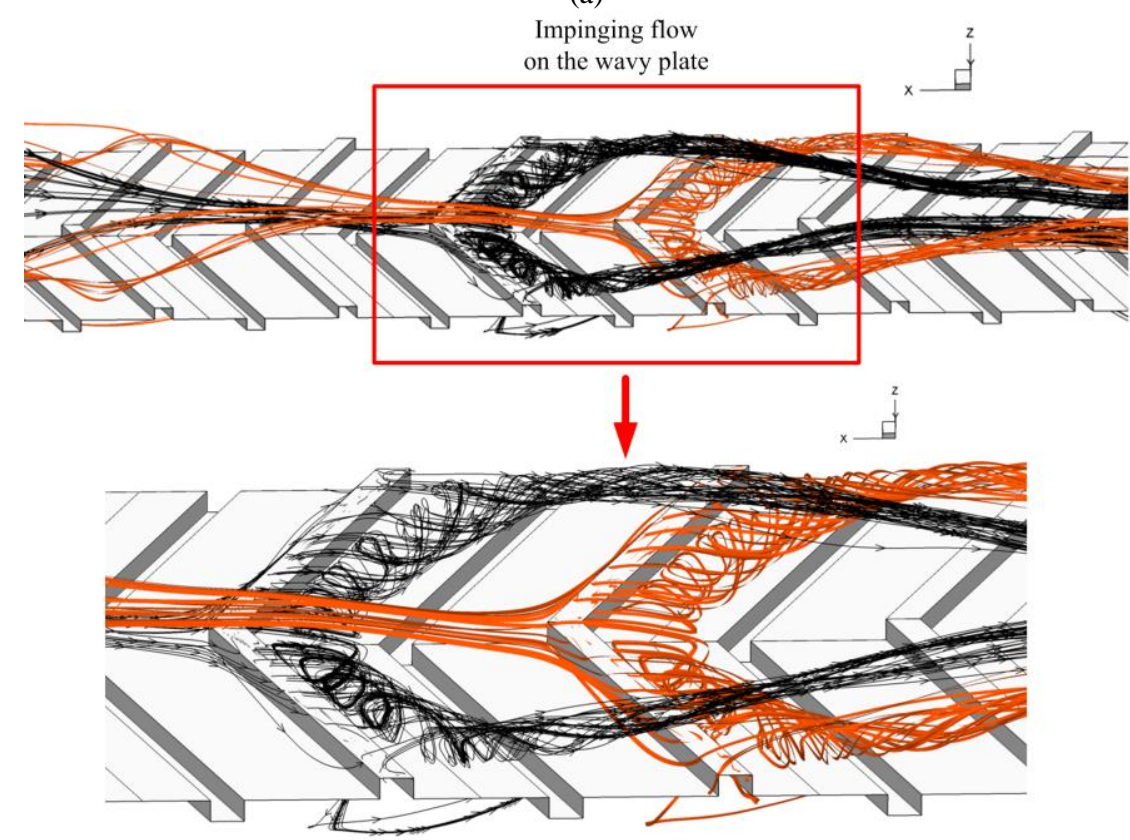

(b)

Fig. 5 Longitudinal vortex flow in the square channel equipped with V-wavy plate for (a) V-Downstream and (b) V-Upstream, at $B R=0.2 \mathrm{Re}=$ 600 and $\mathrm{PR}=1$.

\section{MATHEMATICAL FOUNDATION}

The current problem is solved by finite volume method (SIMPLE algorithm). The square channel flow is governed by the continuity, the Navier-Stokes equations and the energy equation as equations 1, 2 and 3 , respectively.

Continuity equation:

$\frac{\partial}{\partial x_{i}}\left(\rho u_{i}\right)=0$

$$
\frac{\partial\left(\rho u_{i} u_{j}\right)}{\partial x_{j}}=-\frac{\partial p}{\partial x_{i}}+\frac{\partial}{\partial x_{j}}\left[\mu\left(\frac{\partial u_{i}}{\partial x_{j}}+\frac{\partial u_{j}}{\partial x_{i}}\right)\right]
$$

Energy equation:

$\frac{\partial}{\partial x_{i}}\left(\rho u_{i} T\right)=\frac{\partial}{\partial x_{j}}\left(\Gamma \frac{\partial T}{\partial x_{j}}\right)$

where, $\Gamma$ is the thermal diffusivity and is given by:

$$
\Gamma=\frac{\mu}{\operatorname{Pr}}
$$

The continuity and momentum equations are discretized by the power law scheme, while the energy equation is discretized by QUICK scheme. The solutions are determined to be converged when the 
normalized residual values are less than $10^{-5}$ for all variables, but less than $10^{-9}$ only for the energy equation.

The important dimensionless variables for this work are the Reynolds number, friction factor, Nusselt number and thermal enhancement factor, which are written as follows;

The Reynolds number is calculated by

$\operatorname{Re}=\frac{\rho \bar{u} D_{h}}{\mu}$

where, $D_{h}$ is hydraulic diameter of the square channel heat exchanger.

The friction factor, $\mathrm{f}$, is measured by pressure drop, $\Delta \mathrm{p}$, across the length of the periodic module, $\mathrm{L}$, as

$f=\frac{(\Delta P / L) D_{h}}{\frac{1}{2} \rho u^{-2}}$

The heat transfer rate is stated in term of the local Nusselt number, which can be written as equation 7 , while the average Nusselt number can be calculated by equation 8 .

$N u_{x}=\frac{h_{x} D_{h}}{k}$

$N u=\frac{1}{L} \int N u_{x} \partial x$

In laminar flows, the fluid side heat transfer at walls is computed using Fourier's law applied at the walls. FLUENT uses its discrete form:

$q=k_{f}\left(\frac{\partial T}{\partial n}\right)$

and

$h_{x}=\frac{q}{T_{w}-T_{f}}$

Subscript; $\mathrm{w}=$ wall, $\mathrm{f}=$ local fluid and $\mathrm{n}$ is the local coordinate normal to the wall.

The thermal enhancement factor (TEF) is defined as the ratio of the heat transfer coefficient of an augmented surface, $h$, to that of a smooth surface, $\mathrm{h}_{0}$, at an equal pumping power.

$T E F=\left.\frac{h}{h_{0}}\right|_{p p}=\left.\frac{N u}{N u_{0}}\right|_{p p}=\left(N u / N u_{0}\right) /\left(f / f_{0}\right)^{1 / 3}$

The $\mathrm{Nu} 0$ and $f_{0}$ are the Nusselt number and friction factor for the smooth square channel, respectively.

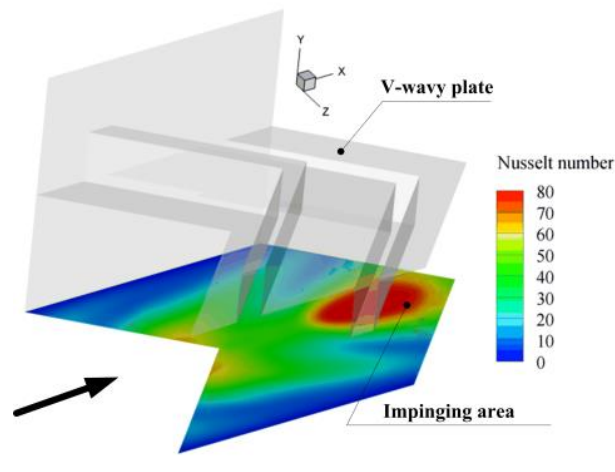

(a)

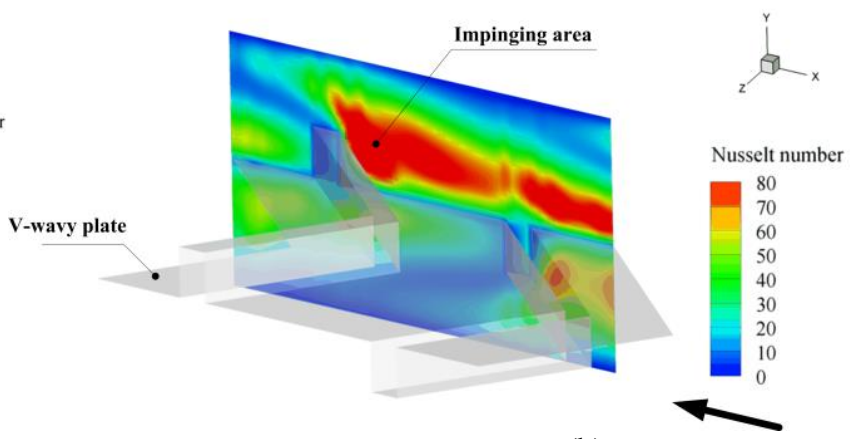

(b)

Fig. $6 \mathrm{Nu}_{\mathrm{x}}$ contour in the square channel equipped with V-wavy plate for (a) V-Downstream and (b) V-Upstream, at $\mathrm{BR}=0.2 \mathrm{Re}=600$ and $\mathrm{PR}=1$.

\section{NUMERICAL VALIDATION}

The numerical model of the square channel heat exchanger equipped with $\mathrm{V}$-wavy plate is validated for both heat transfer rate and friction loss. The numerical validations are divided into two sections; validation of the smooth channel and grid independence test. The numerical validation is an important process to approve the accuracy of the numerical results. The five sets of the computational domain with various grid numbers $(80000,120000,180000,240000$ and 320000) at $\mathrm{BR}=0.15, \mathrm{PR}=1$ and V-Downstream are compared. The numerical results reveal that the computational domains with the number of grid around 120000 to 320000 give very close values for both the Nusselt number and friction factor.

The Nusselt number and friction factor for the smooth channel of the present model are compared with the values from the correlations. The deviations around $\pm 0.07 \%$ and $\pm 0.2 \%$ are detected for the Nusselt number and friction factor, respectively. As the results in this part, it can conclude that the present numerical model has more reliability to predict flow and heat transfer in the heat exchanger equipped with $\mathrm{V}$ wavy plate in the range investigations.

\section{NUMERICAL RESULT}

\subsection{Flow and heat transfer profiles}

The numerical studies of the square channel heat exchanger fitted with various parameters of the $\mathrm{V}$-wavy plate are reported in forms of flow visualization and heat transfer structure. The understanding on the mechanisms in the test section may help to design and develop the compact heat exchanger with high thermal efficiency. Figs. 2 and 3 present the temperature distribution and tangential velocity vector in transverse plane of the square channel fitted with $\mathrm{V}$-wavy plate at $\mathrm{BR}=$ $0.2, \mathrm{x} / \mathrm{H}=0.5$ and $\mathrm{Re}=600$ at various pitch spacing ratios, respectively. The swirling flow appears through the test section when inserted the V-wavy plate in the square channel heat exchanger. The swirling flow effects for the change of the thermal boundary layer on the channel walls. The thermal boundary layer is found to be thinner that is the cause for heat transfer and thermal efficiency improvements. The swirling flow is detected in all investigated cases, but the strength of the flow is not equal. The increment of the blockage ratio and the reduction of the pitch spacing ratio are the reasons for heat transfer rate and thermal performance enhancements due to the increment of the flow strength.

Figs. $4 \mathrm{a}$ and $\mathrm{b}$ illustrate the streamline in transverse plane of the square channel fitted with V-wavy plate for V-Downstream and VUpstream, respectively, at $\mathrm{Re}=800$ and $\mathrm{BR}=0.15$. As the figures, the flow structure includes four main vortex flows and small vortices at four corners of the square channel. The left and right parts of the flow structure appear to be symmetry due to the symmetry configuration. The difference of the V-tip arrangement effects for the change of the flow. The V-Downstream wavy plate can generate the counter-rotating flow with common-flow-down, while the V-Upstream wavy plate can produce the counter-rotating flow with common-flow-up when considering at the lower pair of the flow structure. The change of flow structure influences for the difference of the heat transfer behavior. 
Figs. 5a and $\mathrm{b}$ plot the longitudinal vortex flow in the square channel heat exchanger placed with $\mathrm{V}$-wavy plate for V-Downstream and V-Upstream arrangements, respectively, at $\mathrm{BR}=0.15$ and $\mathrm{Re}=$ 800. The longitudinal flow is found along the test section. The VDownstream wavy plate performs the swirling flow from leading edge of the V-groove to V-tip before move to the next module. The VUpstream wavy surface can create the swirling flow from V-tip to the sidewall after that across around 3-4 modules.

Figs. 6a and $\mathrm{b}$ present the distribution of the local Nusselt number for the V-Downstream and V-Upstream cases, respectively. The peak of

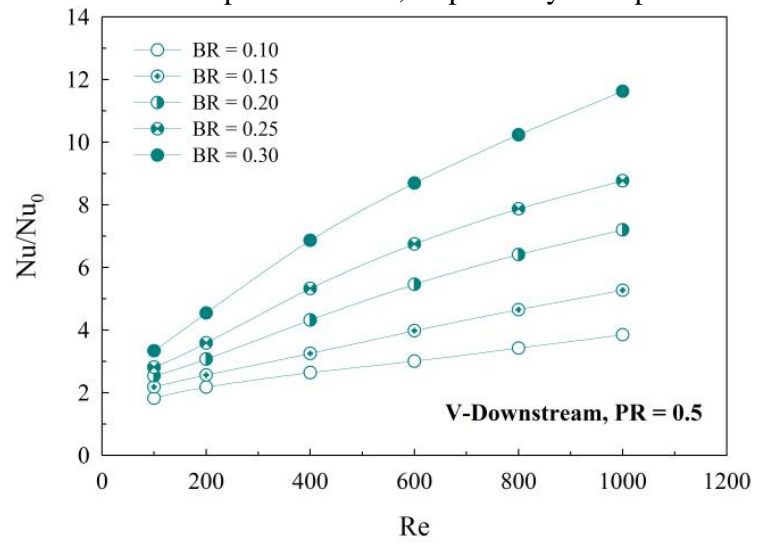

(a) heat transfer rate, which occurs due to the impinging of the flow, is plotted with the red contour. The peak of heat transfer rate is detected at the lower wall of the channel for the V-Downstream, while found at the sidewall for the V-Upstream case. This is because the V-tip arrangement has an effect for the difference of flow structure in the test section. The heat transfer behavior changes when changing the flow configuration in the test section.

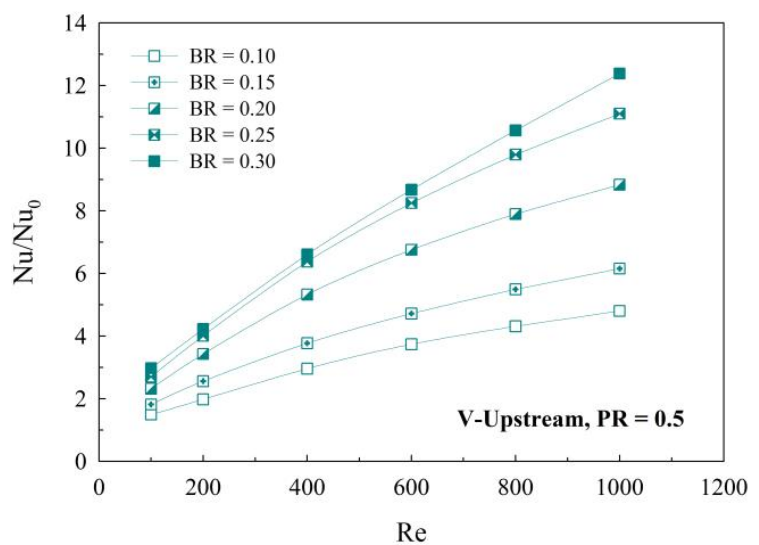

(b)

Fig. $7 \mathrm{Nu} / \mathrm{Nu} 0$ vs $\mathrm{Re}$ for $\mathrm{PR}=0.5$ of (a) V-Downstream and (b) V-Upstream.

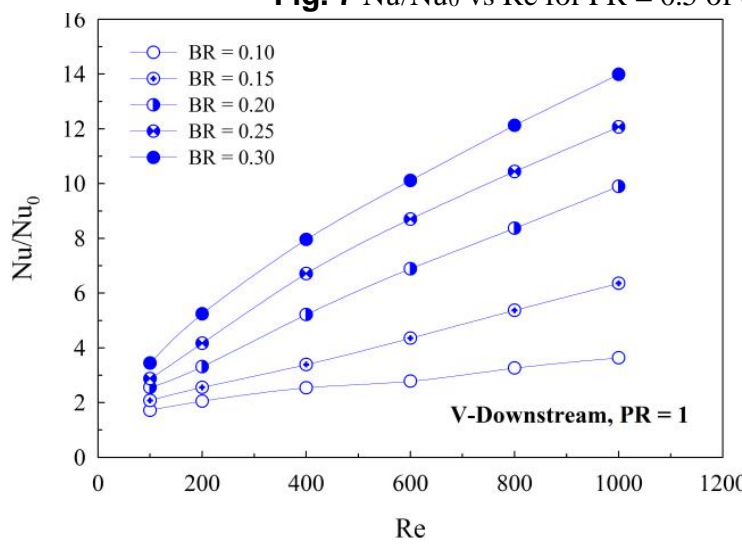

(a)

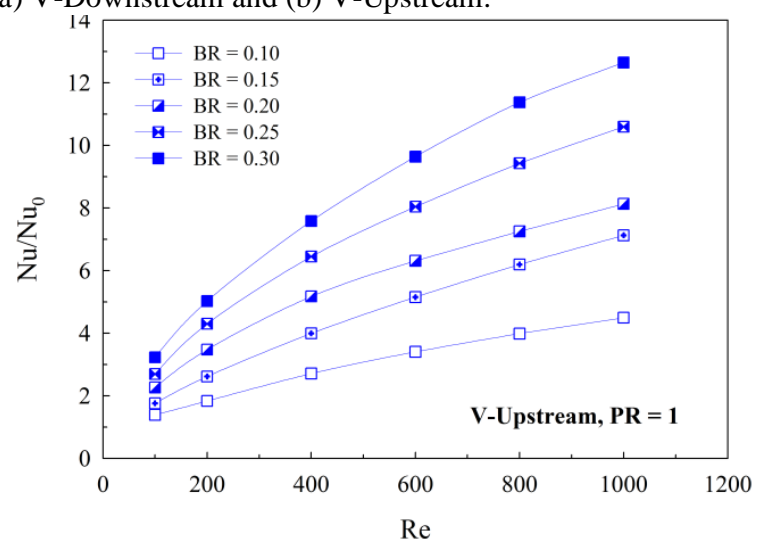

(b)

Fig. $8 \mathrm{Nu} / \mathrm{Nu}_{0}$ vs Re for PR = 1 of (a) V-Downstream and (b) V-Upstream.

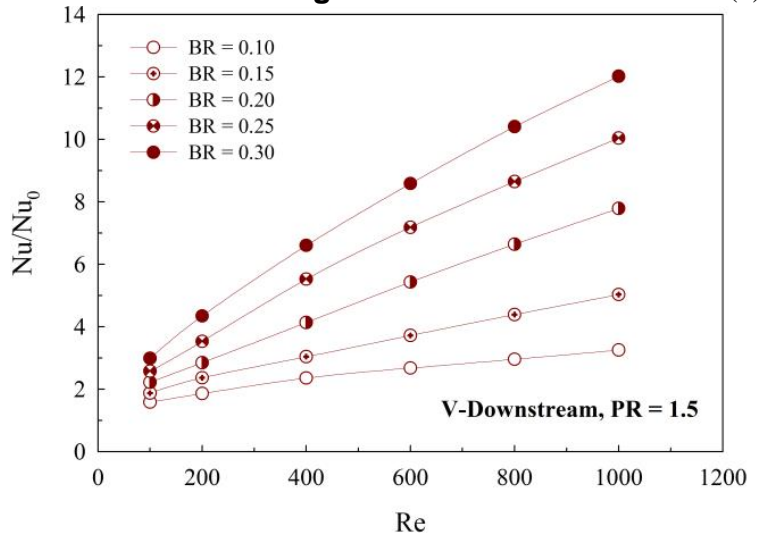

(a)

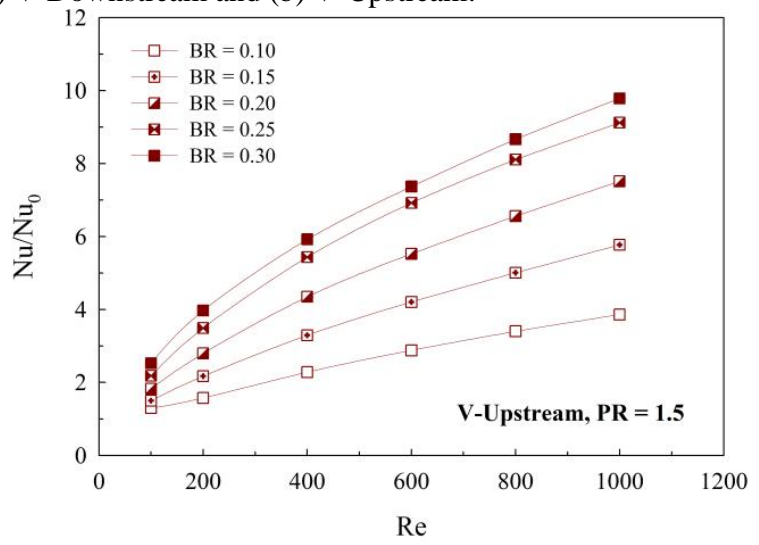

(b)

Fig. $9 \mathrm{Nu} / \mathrm{Nu} 0$ vs Re for PR $=1.5$ of (a) V-Downstream and (b) V-Upstream. 


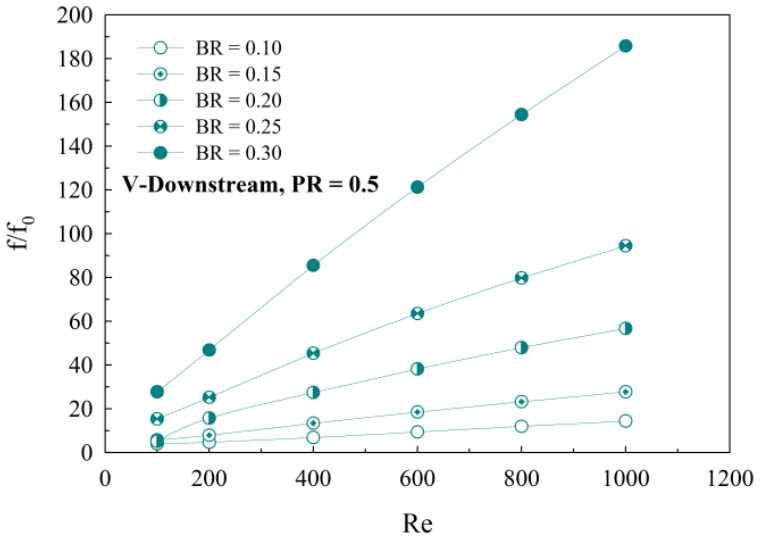

(a)

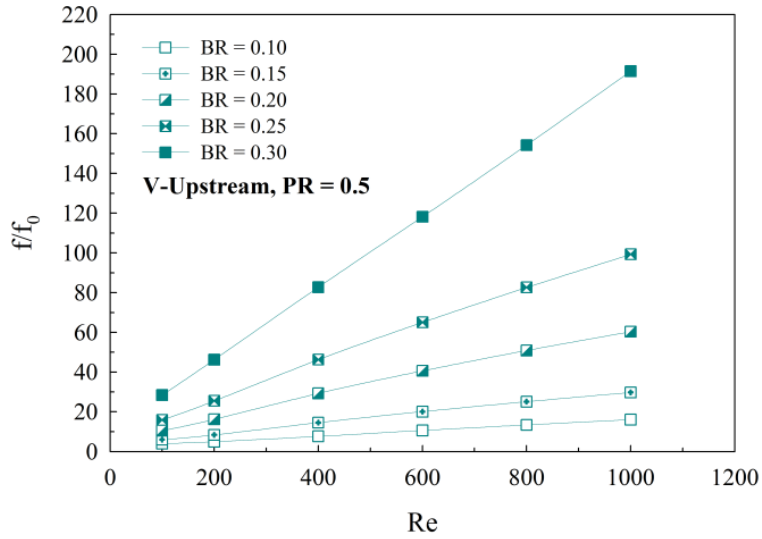

(b)

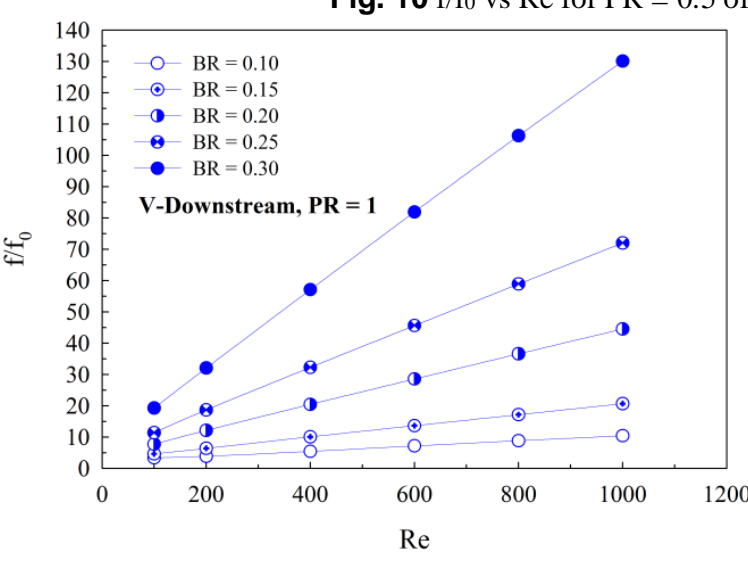

(a)

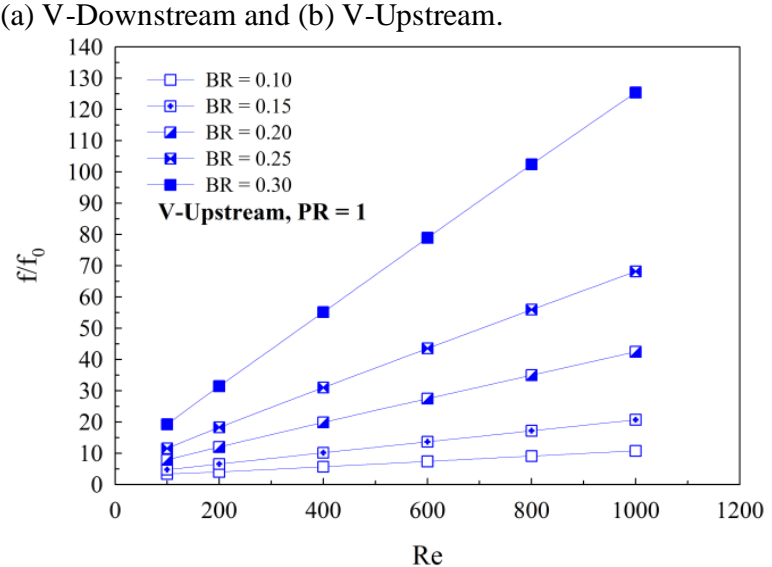

(b)

Fig. 11 f/fo vs Re for PR = 1 of (a) V-Downstream and (b) V-Upstream.

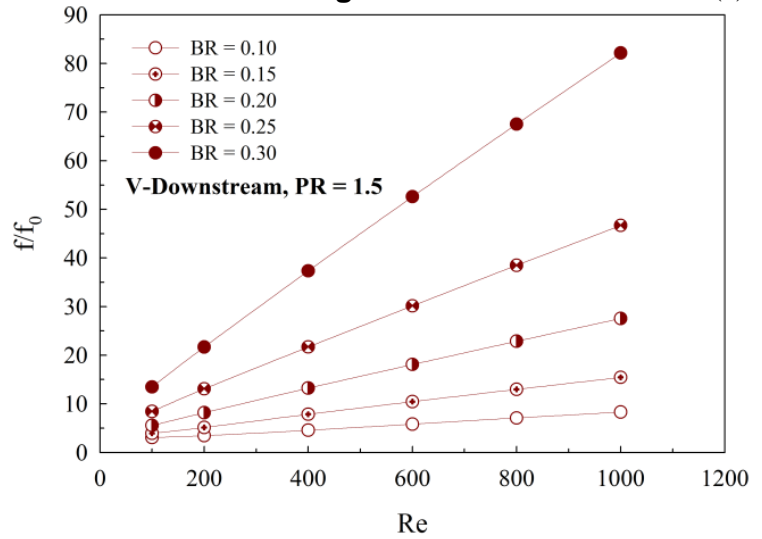

(a)

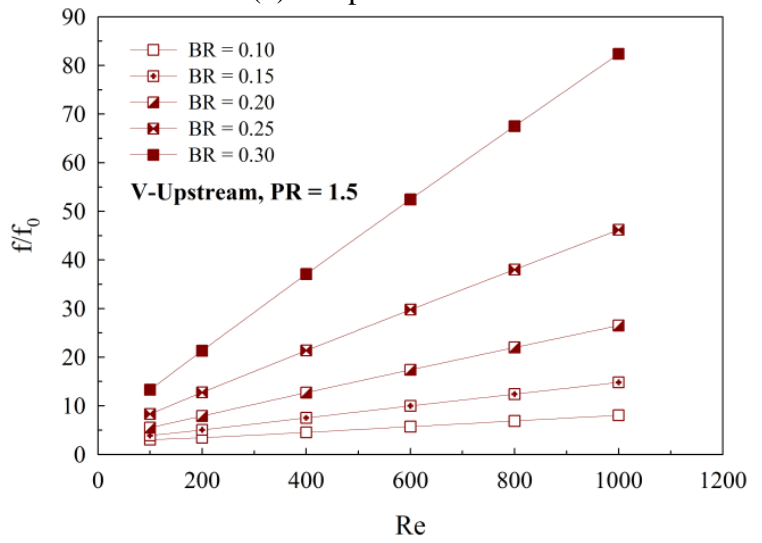

(b)

Fig. 12 f/fo vs Re for PR $=1.5$ of (a) V-Downstream and (b) V-Upstream.

\subsection{Performance assessment}

The heat transfer rate of the square channel heat exchanger equipped with V-wavy plate is reported in terms of the Nusselt number ratio $(\mathrm{Nu} / \mathrm{Nu} 0)$. Figs. 7, 8, and 9 plot the relations of the $\mathrm{Nu} / \mathrm{Nu}_{0}$ with the Reynolds number for the heat exchanger channel equipped with $\mathrm{V}$ wavy plate at $\mathrm{PR}=0.5,1$ and 1.5 , respectively. Normally, the heat transfer rate increases when augmenting the air velocity for all pitch spacing ratios and arrangements. The increment of the air velocity directly effects for the augmentation of the vortex strength, which is the cause for heat transfer enhancement. The maximum and minimum values of the heat transfer rate are detected at $\mathrm{Re}=1000$ and 100 , respectively. The $\mathrm{V}$-wavy plate with the pitch spacing ratio of 0.5 performs the Nusselt number ratio around $1.80-11.60$ and $1.49-$ 12.38, respectively, for V-Downstream and V-Upstream. The heat transfer rate is around $1.71-13.99$ and $1.39-12.65$ times above the smooth channel when inserted the $\mathrm{V}$-wavy plate in the channel with the PR of 1 for V-Downstream and V-Upstream, respectively. The PR of 1.5 for the $\mathrm{V}$-wavy plate in the test section provides the heat transfer rate around $1.08-12.79$ and $1.29-9.78$ times over the smooth channel with no plate for the V-Downstream and V-Upstream arrangements, respectively.

Figs. 10, 11 and 12 plot the relations of the friction factor ratio with the Reynolds number for the square channel heat exchanger equipped with $\mathrm{V}$-wavy plate at PR of $0.5,1.0$ and 1.5 , respectively. In general, the friction loss in the heating section increases when increasing the air velocity. The peak of friction loss is found at the Reynolds number of 1000 , while the opposite result is detected at the Reynolds number around 100 . The friction factor of the square channel 
heat exchanger placed with the $\mathrm{V}$-wavy plate is around $3.91-191.47$, $3.34-130.10$ and $3.04-82.39$ times higher the smooth channel with no plate for the pitch spacing ratio around $0.5,1.0$ and 1.5 , respectively.
The V-Downstream arrangement gives nearly values of the friction loss when compared with the V-Upstream arrangement.

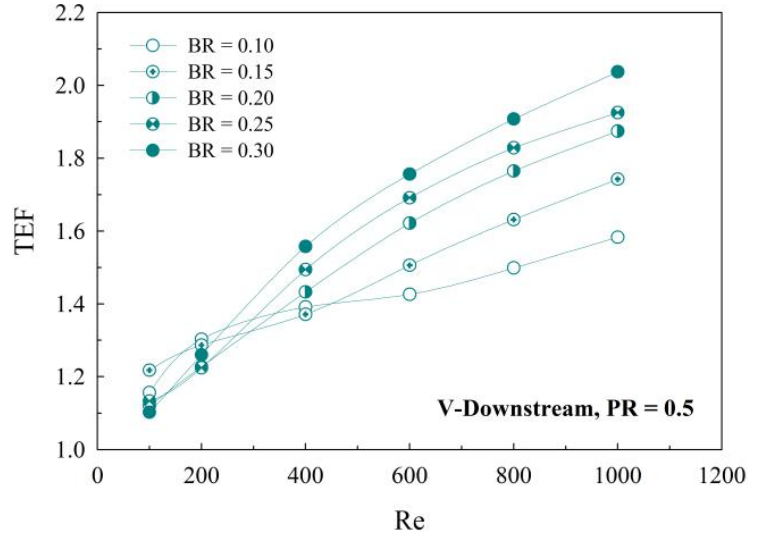

(b)

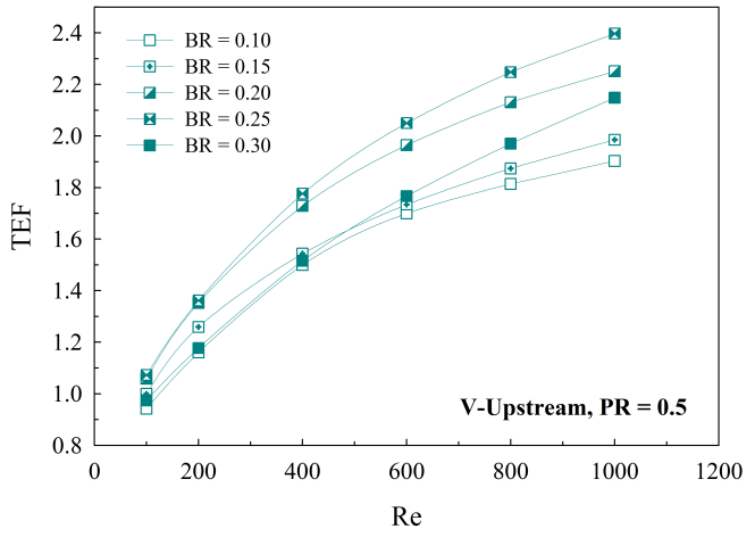

(b)

Fig. 13 TEF vs Re for PR $=0.5$ of (a) V-Downstream and (b) V-Upstream.

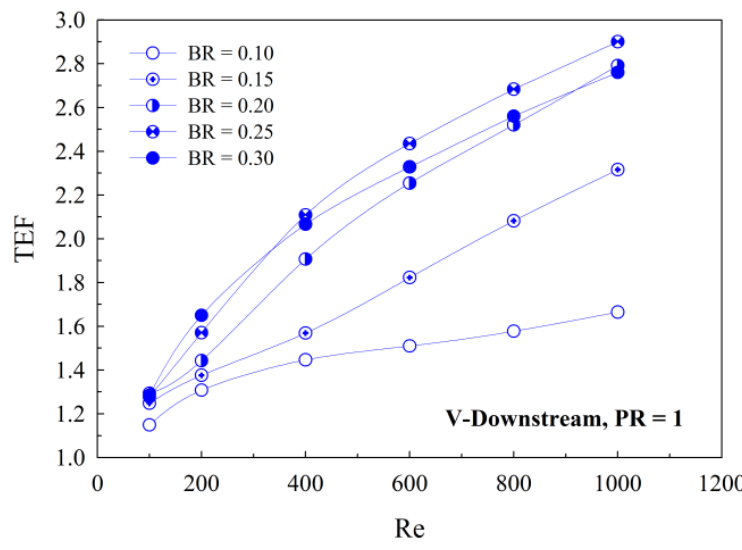

(a)

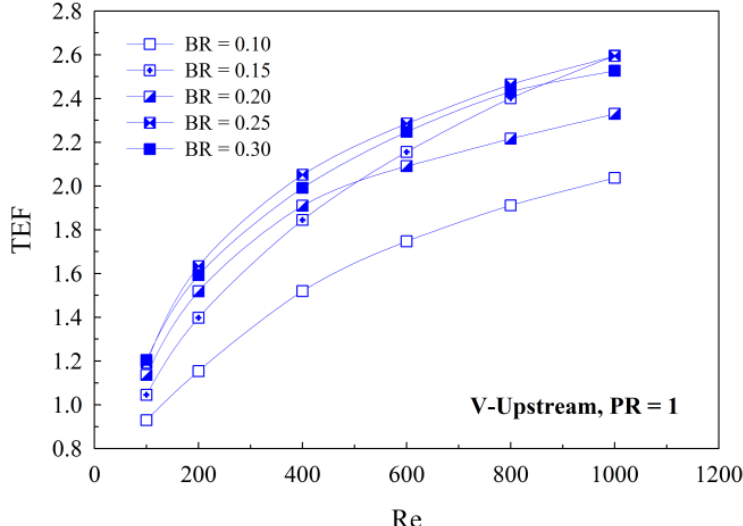

(b)

Fig. 14 TEF vs $R e$ for PR $=1$ of (a) V-Downstream and (b) V-Upstream.

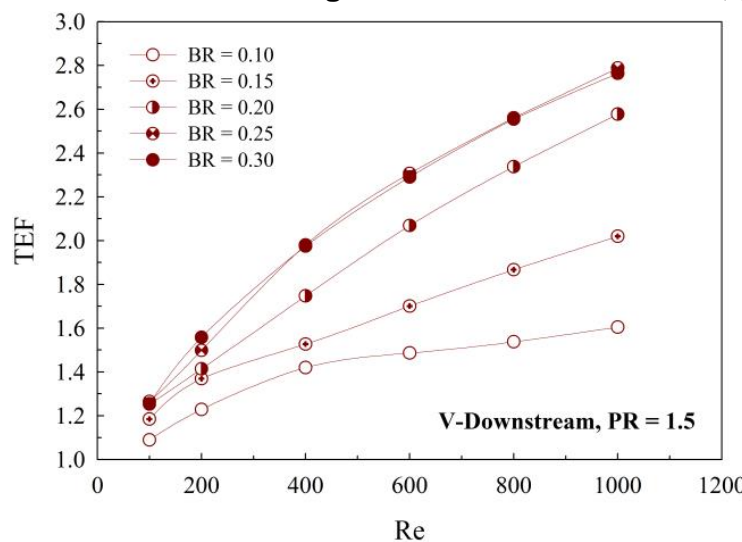

(a)

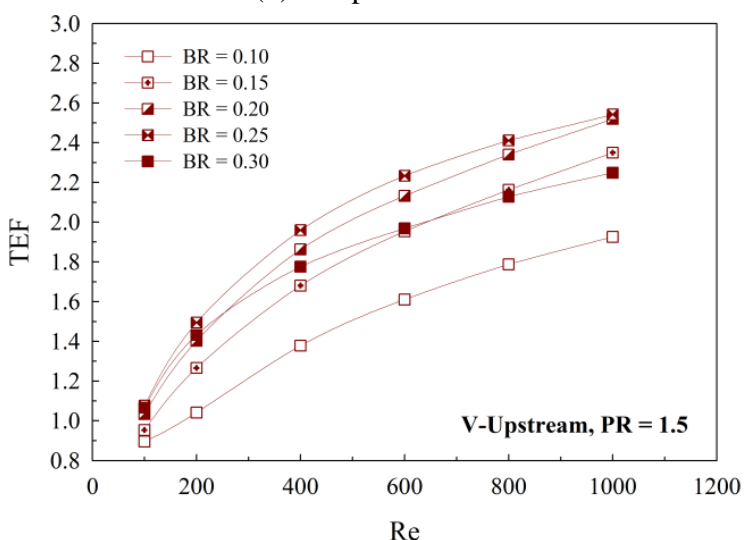

(b)

Fig. 15 TEF vs Re for PR = 1.5 of (a) V-Downstream and (b) V-Upstream.

Figs. 13, 14 and 15 show the relations of the thermal enhancement factor with the Reynolds number at pitch spacing ratios of $0.5,1.0$ and 1.5 , respectively, with various arrangements. The enhancement of the TEF is found when increasing the Reynolds number for all investigated cases. Almost cases, the maximum TEF is detected at the blockage ratio of the V-wavy plate around 0.25 , except for the PR of 0.5 with the VDownstream. The peak of TEF is around 2.04 and 2.40 for the V-wavy plate with the PR of 0.5 for the V-tip pointing downstream and upstream, respectively. The maximum TEF for the PR of 1 is around 2.9 and 2.6, respectively, for V-Downstream and V-Upstream arrangements. The V-wavy plate with the PR of 1.5 gives the optimum TEF around 2.79 for the V-Downstream arrangement, while around 2.54 for the V-Upstream condition.

\section{CONCLUSION}

The numerical examinations on flow structure and heat transfer behavior in the heat exchanger channel equipped with $\mathrm{V}$-wavy plate are presented. The influences of blockage ratio, pitch spacing ratio and flow direction on mechanisms in the test section are investigated for the 
laminar flow region with the Reynolds number around $100-1000$. The finite volume method is selected to solve the present problem. As the numerical results, it can be concluded as follows;

The V-wavy plate can produce the vortex flow or swirling flow through the test section in all investigated cases. The vortex flow is an important factor, which effects for the change of the thermal boundary layer on the heat transfer surface. The heat transfer rate in the channel increases due to the change of the thermal boundary layer.

The augmentations of the Reynolds number and blockage ratio are causes for the increment of the vortex strength that effects for the enhancements of heat transfer rate and thermal performance. The reduction of the pitch spacing ratio can help to increase heat transfer rate due to the increase of the vortex strength.

The flow directions (V-Downstream and V-Upstream arrangements) are an important point for the change of the flow structure and heat transfer behavior in the channel. The difference of the rotation for the vortex flow is detected when change the V-tip arrangement. The suggestion case for the creation of the $\mathrm{V}$-wavy plate in the square channel is $\mathrm{BR}=0.25, \mathrm{PR}=1$ and V-Downstream arrangement when considered at the TEF value.

The manufacturing of the $\mathrm{V}$-wavy plate is more convenient than the other types of the vortex generators such as baffle, rib and winglet. Moreover, the installation and maintenance of the $\mathrm{V}$-wavy plate are easier than the vortex generator, which is placed on the channel wall.

\section{ACKNOWLEDGEMENTS}

The authors would like to thank Assoc. Prof. Dr. Pongjet Promvonge for suggestions. This research was funded by King Mongkut's University of Technology North Bangkok, Contract no. KMUTNB-61DRIVE-041.

BR flow blockage ratio $(=\mathrm{b} / \mathrm{H})$

\section{NOMENCLATURE}

b wavy plate height, $m$

$\mathrm{D}_{\mathrm{h}}$ hydraulic diameter of channel, $\mathrm{m}$

f friction factor

$\mathrm{H}$ channel height, $\mathrm{m}$

h convective heat transfer coefficient, $\mathrm{W} \mathrm{m}^{-2} \mathrm{~K}^{-1}$

$\mathrm{k}$ thermal conductivity, $\mathrm{W} \mathrm{m} \mathrm{m}^{-1} \mathrm{~K}^{-1}$

$\mathrm{Nu}$ Nusselt number $(=\mathrm{hDh} / \mathrm{k})$

$\mathrm{P}$ pitch spacing ratio

$\mathrm{PR}$ pitch ratio $(=\mathrm{P} / \mathrm{H})$

$\mathrm{p}$ static pressure, $\mathrm{Pa}$

Pr Prandtl number $(\operatorname{Pr}=0.707)$

Re Reynolds number

$\mathrm{T}$ temperature, $\mathrm{K}$

$\mathrm{u}_{\mathrm{i}} \quad$ velocity in $\mathrm{x}_{\mathrm{i}}$-direction, $\mathrm{m} \mathrm{s}^{-1}$

$\bar{u}$ mean velocity in channel, $\mathrm{m} \mathrm{s}^{-1}$

\section{Greek letter}

$\alpha \quad$ angle of attack, degree

TEF thermal enhancement factor $\left(=\left(\mathrm{Nu} / \mathrm{Nu}_{0}\right) /\left(\mathrm{f} / \mathrm{f}_{0}\right)^{1 / 3}\right)$

$\rho$ density, $\mathrm{kg} \mathrm{m}^{-3}$

Subscript

in inlet

0 smooth tube

pp pumping power

\section{REFERENCE}

Du, X., Feng, L., Li, L., Yang, L., and Yang, Y., 2014, "Heat Transfer Enhancement of Wavy Finned Flat Tube by Punched Longitudinal Vortex Generators," International Journal of Heat and Mass Transfer, 75, 368-380.

https://doi.org/10.1016/j.ijheatmasstransfer.2014.03.081

Du, X., Feng, L., Yang, Y., and Yang, L., 2013, “Experimental Study on Heat Transfer Enhancement of Wavy Finned Flat Tube with Longitudinal Vortex Generators," Applied Thermal Engineering, 50, $55-62$.

\section{https://doi.org/10.1016/j.applthermaleng.2012.05.024}

Duan, F., Song, K.W., Li, H.R., Chang, L.M., Zhang, Y.H., and Wang, L.B., 2016, "Numerical Study of Laminar Flow and Heat Transfer Characteristics in the Fin Side of the Intermittent Wavy Finned Flat Tube Heat Exchanger," Applied Thermal Engineering, 103, 112-127. https://doi.org/10.1016/j.applthermaleng.2016.04.081

Feilong Zhan, F., Tang, J., Ding, G., and Zhuang, D., 2016, "Experimental Investigation on Particle Deposition Characteristics of Wavy Fin-and-tube Heat Exchangers," Applied Thermal Engineering, 99, $1039-1047$.

https://doi.org/10.1016/j.applthermaleng.2016.01.136

Khoshvaght-Aliabadi, M., Jafari, A., Sartipzadeh, O., and Salami, M., 2016, "Thermal-hydraulic Performance of Wavy Plate-fin Heat Exchanger using Passive Techniques: Perforations, Winglets, and Nanofluids," International Communications in Heat and Mass Transfer, 78, 231-240.

https://doi.org/10.1016/j.icheatmasstransfer.2016.09.019

Kim, G.W., Lim, H.M., and Rhee, G.H., 2016, "Numerical Studies of Heat Transfer Enhancement by Cross-cut Flow Control in Wavy Fin Heat Exchangers," International Journal of Heat and Mass Transfer, 96, 110-117.

https://doi.org/10.1016/j.ijheatmasstransfer.2016.01.023

Li, M.J., Zhang H., Zhang, J., Mu Y.T., Tian, E., Dan, D., Zhang, X.D., and Tao, W.Q., 2018, "Experimental and Numerical Study and Comparison of Performance for Wavy Fin and a Plain Fin with Radiantly Arranged Winglets Around Each Tube in Fin-and-tube Heat Exchangers," Applied Thermal Engineering, 133, 298-307. https://doi.org/10.1016/j.applthermaleng.2018.01.012

Lotfi, B., Sundén, B., and Wang, Q., 2016, “An Investigation of the Thermo-hydraulic Performance of the Smooth Wavy Fin-and-elliptical Tube Heat Exchangers Utilizing New Type Vortex Generators," Applied Energy, 162, 1282-1302.

https://doi.org/10.1016/j.apenergy.2015.07.065

Priyam, A., and Chand, P., 2016, "Thermal and Thermohydraulic Performance of Wavy Finned Absorber Solar Air Heater," Solar Energy, 130, 250-259.

https://doi.org/10.1016/j.solener.2016.02.030

Priyam, A., and Chand, P., 2018, "Effect of Wavelength and Amplitude on the Performance of Wavy Finned Absorber Solar Air Heater," Renewable Energy, 119, 690-702. https://doi.org/10.1016/j.renene.2017.12.010

Song, Y., Asadi, M., Xie, G., and Rocha, L.A.O., 2015, "Constructal Wavy-fin Channels of a Compact Heat Exchanger with Heat Transfer Rate Maximization and Pressure Losses Minimization," Applied Thermal Engineering, 75, 24-32.

https://doi.org/10.1016/j.applthermaleng.2014.05.027

Xiao, L., Wu, T., Feng, S., Du, X., and Yang, L., 2017, "Experimental Study on Heat Transfer Enhancement of Wavy Finned Flat Tubes by Water Spray Cooling," International Journal of Heat and Mass Transfer, 110, 383-392.

https://doi.org/10.1016/j.ijheatmasstransfer.2017.03.054

Xu, C., Yang, L., Li, L., and Du, X., 2015, "Experimental Study on Heat Transfer Performance Improvement of Wavy Finned Flat Tube," Applied Thermal Engineering, 85, 80-88.

https://doi.org/10.1016/j.applthermaleng.2015.02.024

Zhang, Q., Qin, S., and Ma, R., 2016, "Simulation and Experimental Investigation of the Wavy Fin-and-tube Intercooler," Case Studies in Thermal Engineering, 8, 32-40.

https://doi.org/10.1016/j.csite.2016.04.003 